\title{
The perceived influence of cost-offset community-supported agriculture on food access among low-income families
}

\author{
Michelle J White ${ }^{1, *}$, Stephanie B Jilcott Pitts ${ }^{2}$, Jared T McGuirt ${ }^{3}$, Karla L Hanson ${ }^{4}$, \\ Emily H Morgan ${ }^{4}$, Jane Kolodinsky ${ }^{5}$, Weiwei Wang ${ }^{5}$, Marilyn Sitaker ${ }^{6}$, \\ Alice S Ammerman ${ }^{7}$ and Rebecca A Seguin ${ }^{4}$ \\ ${ }^{1}$ Division of General Pediatrics and Adolescent Medicine, Department of Pediatrics, School of Medicine, University \\ of North Carolina at Chapel Hill, 231 MacNider, CB\#7225, Chapel Hill, NC 27599-7225, USA: ${ }^{2}$ Brody School of \\ Medicine, East Carolina University, Greenville, NC, USA: ${ }^{3}$ Department of Nutrition, The University of North Carolina \\ at Greensboro, Greensboro, NC, USA: ${ }^{4}$ Division of Nutritional Sciences, Cornell University, Ithaca, NY, USA: \\ ${ }^{5}$ Department of Community Development and Applied Economics, University of Vermont, Burlington, VT, USA: \\ ${ }^{6}$ Ecological Agriculture and Food Systems, The Evergreen State College, Olympia, WA, USA: ${ }^{7}$ Center for Health \\ Promotion and Disease Prevention, University of North Carolina at Chapel Hill, Chapel Hill, NC, USA
}

Submitted 17 February 2018: Final revision received 18 May 2018: Accepted 4 June 2018: First published online 11 July 2018

\begin{abstract}
Objective: To examine perspectives on food access among low-income families participating in a cost-offset community-supported agriculture (CO-CSA) programme.

Design: Farm Fresh Foods for Healthy Kids (F3HK) is a multicentre randomized intervention trial assessing the effect of CO-CSA on dietary intake and quality among children from low-income families. Focus groups were conducted the end of the first CO-CSA season. Participants were interviewed about programme experiences, framed by five dimensions of food access: availability, accessibility, affordability, acceptability and accommodation. Transcribed data were coded on these dimensions plus emergent themes.

Setting: Nine communities in the US states of New York, North Carolina, Washington and Vermont.

Subjects: Fifty-three F3HK adults with children.

Results: CSA models were structured by partner farms. Produce quantity was abundant; however, availability was enhanced for participants who were able to select their own produce items. Flexible CSA pick-up times and locations made produce pick-up more accessible. Despite being affordable to most, payment timing was a barrier for some. Unfamiliar foods and quick spoilage hindered acceptability through challenging meal planning, despite accommodations that included preparation advice.

Conclusions: Although CO-CSA may facilitate increased access to fruits and vegetables for low-income families, perceptions of positive diet change may be limited by the ability to incorporate share pick-up into regular travel patterns and meal planning. Food waste concerns may be particularly acute for families with constrained resources. Future research should examine whether CO-CSA with flexible logistics and produce self-selection are sustainable for low-income families and CSA farms.
\end{abstract}

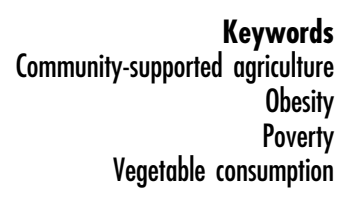

A diet rich in fruits and vegetables is associated with lower risk of obesity and nutrition-related chronic diseases ${ }^{(1,2)}$. Low-income individuals generally consume fewer fruits and vegetables compared with those of higher socio-economic status, contributing to a higher prevalence of obesity in lowincome children and adults ${ }^{(3,4)}$. Individual-level disparities in fruit and vegetable consumption are mediated in part by neighbourhood-level factors, as low-income neighbourhoods tend to offer fewer opportunities to purchase goodquality, affordable produce compared with higher-income neighbourhoods ${ }^{(5,6)}$. Effective and sustainable strategies to increase fruit and vegetable consumption among lowincome families with children remain elusive potentially due to failure to address multiple dimensions of food 
$\operatorname{access}^{(7,8)}$. Adapting a concept proposed by Penchansky and Thomas, access may be defined as foods that are readily available, in a geographically accessible location, in a setting that is acceptable to consumers, at a price perceived as affordable, using a delivery model that accommodates consumer needs ${ }^{(9,10)}$.

Direct-to-consumer market venues such as communitysupported agriculture (CSA) and farmers' markets are an alternative to conventional retail food outlets, providing high-quality produce as well as a living wage for local farmers $^{(11,12)}$. Shopping at direct-to-consumer venues has been demonstrated to improve vegetable consumption and facilitate healthy eating behaviours ${ }^{(13-15)}$. Traditionally, CSA members pay a lump sum at the beginning of the season and receive a 'share' of the harvest, typically on a weekly or biweekly basis throughout the growing season. CSA members tend to educated, white and affluent ${ }^{(16)}$, with a minority of lower-income participants ${ }^{(17-19)}$. Low-income families may perceive CSA as too expensive due in part to the lump sum payment structure ${ }^{(20)}$. Subsidies and price discounts have been successful in removing financial barriers to produce purchase and consumption when offered to low-income families in conventional retail settings as well as famers' markets ${ }^{(21,22)}$. Therefore, offsetting the cost of CSA through subsidies paired with a non-traditional payment strategy may be an effective means of leveraging the strengths of CSA to improve fruit and vegetable access and consumption for low-income families.

Only a handful of studies explore the experiences of urban and rural low-income families within CSA and their potential role in addressing food access ${ }^{(17,23-25)}$. These studies have tended to focus on member satisfaction and nutrition behaviours, with less emphasis on dimensions of food access beyond geographic proximity and affordability $^{(10)}$. To more fully describe the complexity of food access beyond these two factors, we employ the multidimensional definition of access described above ${ }^{(9)}$. Exploring each dimension of access within a subsidized CSA shareholder cohort may reveal previously undescribed access barriers and indicate CSA strategies that may lead to a more sustained participation and increase in fruit and vegetable consumption in low-income families ${ }^{(26)}$.

Farm Fresh Foods for Healthy Kids (F3HK) is a randomized multicentre intervention trial for low-income families with children occurring in partnership with twelve farms in the US states of New York, North Carolina, Washington and Vermont ${ }^{(27)}$. The overall goal of the intervention is to prevent childhood obesity through increased fruit and vegetable intake. Trial participants were randomized into a cost-offset CSA (CO-CSA) membership group ('intervention group') and a delayed intervention control group. The intervention group received a subsidized CSA share combined with food preparation and nutrition education. Additional details on the design and methods of the intervention have been published previously ${ }^{(27)}$. The present paper describes findings from an in-depth qualitative analysis of focus groups among F3HK intervention participants after completion of the CSA season, using the five dimensions of food access as an analytic framework.

\section{Methods}

\section{Recruitment and conduct of focus groups}

Focus group participants were recruited from F3HK adults with children at each partner farm after the first season of CSA membership to evaluate how experiences with the CSA and intervention classes impacted perceived food access. Per the trial's inclusion criteria, all were the parent or legal guardian of at least one child aged 2-12 years. F3HK participants were invited to focus groups via email, telephone call and text message. Focus groups met at community locations and participants were compensated \$US 25 for their time. If a focus group was attended by fewer than $50 \%$ of farm participants, a second focus group for that farm was scheduled using the same recruitment strategy. Formal childcare was not provided, but children were allowed to sit with their parent or guardian during the session and materials for quiet play were available. Participants gave their consent for participation and audio recording prior to each focus group. As part of the consent process, participants were informed that participation in the focus groups was voluntary and would not affect their participation in the F3HK trial. Focus group discussions were led by study staff who received facilitation training that was standardized across all sites.

A single discussion guide was created for all focus groups, based on the 5A framework of food access described by Caspi et al. ${ }^{(10)}$ : accessibility, affordability, acceptability, accommodation and availability. Accessibility questions concerned barriers and facilitators to CSA pick-up, including location, timing and organizational logistics. Affordability questions addressed the cost and value of CSA produce. Acceptability questions covered perceived quality of the produce and responses to unfamiliar produce. Accommodation and availability questions concerned perceptions of interactions with the farmer and farm staff and the variety and quantity of CSA produce, respectively. While participants were asked to share their experience with the education classes offered as part of the intervention, this topic was not the focus of the present analysis and is not reported herein.

Focus group audio recordings were transcribed verbatim. Demographic information on participants was drawn from baseline data from the intervention. Details on the collection of these data have been reported elsewhere ${ }^{(27)}$.

\section{Qualitative analysis}

Transcripts were imported into the qualitative data analysis package Atlas.ti version 1.6.0, to support analysis. Four 
members of the study team analysed the transcripts. The lead author (M.J.W.) performed an initial review of the data. Two transcripts from different sites were then coded deductively based on Caspi et al.'s 5A framework ${ }^{(10)}$ by four members of the analytic team (S.B.J.P., J.T.M., S.C., M.J.W.). Study team members then discussed key concepts within this framework as well as emerging ideas and created a consensus codebook of deductive and inductive codes. Each of the transcripts was then double coded by two study team members of different disciplinary backgrounds (paediatric physician (M.J.W.); nutrition scientist (S.B.J.P.)) utilizing the consensus codebook. Team members communicated frequently to discuss and refine key concepts and resolve coding conflicts and discrepancies during the coding process. Categories and themes were then developed upon further review of the coded data. Negative cases and investigator bias (reflexivity) were also addressed during these discussions ${ }^{(28)}$. The final themes presented herein were determined using the Caspi et al. framework and by selecting emerging themes based on the frequency with which themes appeared across all focus groups, as well as potential relevance to future interventions.

\section{Results}

\section{Focus group demographics}

Fourteen focus groups were attended by fifty-three adults with children who participated in CO-CSA partner farms across four states (Table 1). Most focus group participants were female and had one or two children at home. Sixtyfour per cent of participants were white/non-Hispanic. Approximately half of the participants were employed outside their homes. Sixty-seven per cent of participants reported an annual household income of less than \$US 35000 .

\section{Accessibility: barriers and facilitators to picking up produce}

Getting to the pick-up site was a significant challenge for participants across all focus groups (Table 2). Distance was a major obstacle for picking up CSA shares, as well as the inability to integrate the pick-up into normal travel routines, including children's school and extracurricular activities. For many participants, produce pick-up was 'an extra errand' requiring more 'distance travelled'. Parking availability and proximity to the pick-up location were important. Poor on-site organization was challenging, as some participants mentioned struggling to cope with long lines and confusion regarding share contents and payments. Participants at nearly all focus groups reported relying on friends or family members to assist with picking up produce due to busy schedules or out-of-town engagements.
Table 1 Demographics of focus group participants: adults with children ( $n$ 53) participating in a cost-offset community-supported agriculture (CO-CSA) programme, as part of the Farm Fresh Foods for Healthy Kids (F3HK) multicentre randomized intervention trial, in nine communities in the US states of New York, North Carolina, Washington and Vermont, November and December 2016

\begin{tabular}{|c|c|c|}
\hline Characteristic & $\%$ & $n$ \\
\hline \multicolumn{3}{|l|}{ Location of CO-CSA farm } \\
\hline New York & 47 & 25 \\
\hline North Carolina & 32 & 17 \\
\hline Washington & 6 & 3 \\
\hline Vermont & 15 & 8 \\
\hline Total & 100 & 53 \\
\hline Female & 94 & 50 \\
\hline \multicolumn{3}{|l|}{ Race/ethnicity } \\
\hline Black & 19 & 10 \\
\hline White, non-Hispanic & 64 & 34 \\
\hline Other or Unknown & 17 & 9 \\
\hline \multicolumn{3}{|l|}{ Number of children at home } \\
\hline 1 & 28 & 15 \\
\hline 2 & 36 & 19 \\
\hline 3 & 17 & 9 \\
\hline 4 or more & 19 & 10 \\
\hline \multicolumn{3}{|l|}{ Employment status } \\
\hline Employed & 45 & 24 \\
\hline Unemployed, student or retired & 11 & 6 \\
\hline Homemaker & 43 & 23 \\
\hline \multicolumn{3}{|l|}{ Annual household income } \\
\hline Less than \$US 20000 & 33 & 17 \\
\hline \$US 20000-34 999 & 34 & 18 \\
\hline \$US 35000-49999 & 27 & 14 \\
\hline \$US 49999-74999 & 6 & 3 \\
\hline
\end{tabular}

Accessibility of CSA pick-up was facilitated by pick-up locations that were easily integrated into travel routines and offered easy parking and efficient site organization. Clear labelling was helpful for those who were able to self-select share contents. Those with preselected produce appreciated having pre-packed boxes or totes for ease of transport.

Across all focus groups, participants strongly desired flexibility of pick-up site and time. Although some CSA offered the option of picking up at either a central location or the CSA farm, others were limited to one location. Similarly, longer hours for evening pick-ups were more convenient to the work schedules of some participants. Participants in one focus group unanimously recommended home delivery to mitigate the logistical challenges of travelling to a location after work with children in tow. Others recommended that pick-up coincide with the classes that were also offered as part of the intervention.

\section{Affordability: cost and value of community- supported agriculture produce}

When asked directly about the price of the CSA, most of the participants in all focus groups thought that the subsidized price of the CSA was affordable to them. In fact, the prospect of receiving low-cost produce was what attracted many to the intervention. Participants believed that they were saving money, particularly compared with grocery store prices. 
Table 2 Key themes, definitions and illustrative quotes from focus group discussions conducted among adults with children ( $n$ 53) participating in a cost-offset community-supported agriculture programme, as part of the Farm Fresh Foods for Healthy Kids (F3HK) multicentre randomized intervention trial, in nine communities in the US states of New York, North Carolina, Washington and Vermont, November and December 2016

\begin{tabular}{lll}
\hline Theme Definition & Illustrative quotes \\
\hline
\end{tabular}

Accessibility Barriers and facilitators to picking 'I think it was just difficult for me 'cause like, I finish work at like three, then get my son up produce from the bus, but I still have a whole, like hour something, to kill, [...] and he's like "Mommy, we need the vegetables!", driving me crazy, you know, sometimes you just wanna go home [laughter].'

'It's literally a mile from my house. It was very easy to just hop in the car, hop over there in the afternoon and then be done with it for the day. I know that's not the case for everyone.'

Affordability Cost and value of CSA produce 'People with more money can afford better, healthier foods! And it's really frustrating that I was not able to do that before [joining the CSA]. But at the same time, if I'm going and all that's left is kohlrabi, [inaudible] I'm just throwing my money away at that point.'

'I thought that the cost was very reasonable. [...] We were making more food than we normally were but it didn't impact the cost for us. To me it's a really big tool.'

'Like when I go to the grocery store and I spend ten dollars, I'm buying what I know I like, rather than just spending whatever that's costing, and half of it, I don't know what it is and I'm not gonna eat it.'

Acceptability Quality and responses to unfamiliar 'A lot of the produce we got over the summer ... made it onto the grill. Like with the CSA produce kohlrabi, I fixed it up with the potatoes and some seasoning and it turned out really nice.'

'I know that they are like organic so they don't use pesticides [...] during the end of it there were a lot of cabbage aphids which I wasn't too certain on how to go about removing them [...], so I threw away a lot during the end of it because of that.'

'Lot of times [CSA produce] would just go bad and I would add them to my compost area and I'm like "Sorry, I don't know what to do with you. You're cute but I have no idea what to do with you."'

'The kohlrabi. I made fritters with them and they were wonderful. Huge hit. I fried them up with the onions and then served them with applesauce from the apples and everyone ate them up.'

'Anytime I would bring the CSA home [to my kids] and ... they would just be like looking through it, "What did we get this week? What did we get?" And [my daughter] especially was like, "Well I'm going to make a smoothie out of that, that's for sure." [...] It was just really fun to watch.'

'That's the thing. Having to find a way to use it all [...] or feeling bad about it going to waste or throwing it away or something like that. Trying to find a way to give it to somebody [laughter].'

Accommodation Financial or logistical interactions with farmer or farm staff

'[The farmer] always ... I felt that if you were unsure about something or if you stood in front of a bin long enough [...] She would come over and say, "Oh that is such-andsuch and this is a good way to use it."'

'[The farmer] was helpful, answered all of our questions, explained how things were growing and how they're seasonal.'

'Because budgeting EBT is done weekly, that's how it goes in my family. Things run out as it gets toward the end of the month. It would have nice to have been able to pay for it all at once, so I knew that I could still receive my weekly boxes.'

Availability Variety and quantity of CSA

'I think we got overwhelmed with the kale at the end, it seemed like it was going okay but at the end it just seemed like we were getting a lot every week, and it was too much, some of it did end up going to waste.'

'I didn't know how much we would be receiving, like I wasn't sure, just signing up, like how much of our grocery share it's gonna be, but I was pleasantly surprised, I was worried it would be like, a small amount, but I think it was a good bit.'

'I got two. I didn't know how much stuff is actually in a share. You know, it said so many units, but here I'm thinking okay we're going to get maybe three apples. [...] I didn't think those boxes were going to be packed to the max.'

'I mean to a certain extent it was fun to have like new things, but [...] everybody agrees, there should be some sort of option like if there's something you're definitely not going to eat $[. .$.$] because growing the things that we're not going to$ touch is kind of wasteful.'

CSA, community-supported agriculture; EBT, electronic benefit transfer.

However, satisfaction with cost was balanced by a sense that the lack of choice inherent in preselected weekly shares decreased the value of the produce received:

'Like when I go to the grocery store and I spend ten dollars, I'm buying what I know I like, rather than just spending whatever that's costing, and half of it, I don't know what it is and I'm not gonna eat it.' (NC, Farm 1)

Notably, cost and quality were often connected in focus group discussions because participants found it more acceptable to spend money for produce of high quality. 


\section{Acceptability: quality and suitability of community-supported agriculture produce}

Within the theme of acceptability, two salient themes emerged: (i) perceived quality of the produce; and (ii) responses to unfamiliar foods. Participants' responses to unfamiliar foods fell into three sub-themes: creative food preparation, online or farm resources, and donation and waste.

\section{Perceived quality of the produce}

The majority of participants in all focus groups equated quality with the appearance of produce and time to spoilage. The occasional presence of bugs, slugs and mould were perceived as evidence of poor quality. Spoilage was of particular concern, as participants in five focus groups believed that the CSA produce spoiled faster than grocery store produce:

'I know that they are like organic so they don't use pesticides [...] during the end of it there were a lot of cabbage aphids which I wasn't too certain on how to go about removing them [...], so I threw away a lot during the end of it because of that.' (NY, Farm 1)

Participants in all focus groups were interested in learning to preserve produce through freezing, canning or pickling. Although some of these skills were part of the intervention curriculum, participants in five focus groups described detailed storage and preservation tips including 'magic tricks' from farmers such as how to preserve coriander by putting it into a jar and covering it with a bag. One participant stated that storage skills would have been very helpful as an initial class prior to the receipt of produce.

\section{Response to unfamiliar foods}

Receiving unfamiliar foods was a significant theme across all focus groups as participants readily described receiving boxes with produce that they could not identify or name:

'Lot of times [CSA produce] would just go bad and I would add them to my compost area and I'm like "Sorry, I don't know what to do with you. You're cute but I have no idea what to do with you."' (NY, Farm 1)

Creative food preparation. Many participants described difficulty introducing unfamiliar foods to children and other family members. However, unfamiliar foods were a catalyst for creative food preparation by participants in approximately one-third of focus groups. Some experimented by utilizing recipes for vegetables similar in appearance or quality:

'The kohlrabi. I made fritters with them and they were wonderful. Huge hit. I fried them up with the onions and then served them with applesauce from the apples and everyone ate them up.' (NY, Farm 3)
Others mixed the new vegetables into other dishes, such as seeds and vegetables blended into juices and smoothies. Participants in three focus groups described how their children joined the creative process, assisting with the preparation of new foods:

'Anytime I would bring the CSA home [to my kids] and ... they would just be like looking through it, "What did we get this week? What did we get?" And [my daughter] especially was like, "Well I'm going to make a smoothie out of that, that's for sure." [...] It was just really fun to watch.' (NY, Farm 2)

Farm and online resources. Participants in nearly all focus groups reported seeking out resources to learn how to cook and prepare their produce in addition to the intervention's food preparation and nutrition classes. Farmers and farm staff often provided information (overlapping with the theme of accommodation). Online searches, Facebook and older family members were also resources. During nearly all focus group sessions participants were eager to discuss the different recipe discoveries they had made, demonstrating a desire to swap recipes and tips with other participants.

Donations and waste. Participants in eight of fourteen focus groups mentioned donating or not using produce. Notably, this could occur with unfamiliar as well as familiar foods. Although amounts varied, several participants admitted giving or throwing away a portion of their share because they did not know how to utilize it or there was more than their family could consume. One participant stated that she threw away or gave away $40 \%$ of each of her weekly shares:

'That's the thing. Having to find a way to use it all [...] or feeling bad about it going to waste or throwing it away or something like that. Trying to find a way to give it to somebody [laughter].' (NY, Farm 3)

Participants across all focus groups were motivated to use unfamiliar items to justify the money they had spent.

\section{Accommodation: perceptions of interactions with farmer or farm staff}

Within the theme of accommodation, two key sub-themes emerged: (i) financial interactions; and (ii) logistical interactions with the farmer or farm staff.

\section{Financial interactions}

Participants in five focus groups mentioned a desire for more flexible payment methods and frequency of payments. These factors were important in addition to overall price. Paying online, in person via credit card or by electronic benefit transfer (EBT) were all preferred formats. Participants in multiple focus groups relied upon EBT and found it helpful that farms accepted EBT payments; 
however, one participant noted that her EBT ran out prior to the end of the month, making it difficult to purchase the CSA produce:

'Because budgeting EBT is done weekly, that's how it goes in my family. Things run out as it gets toward the end of the month. It would have been nice to have been able to pay for it all at once, so I knew that I could still receive my weekly boxes.' (WA, Farm 1)

Participants in two focus groups mentioned the importance of their relationship with the farmer in financial interactions. They appreciated working with farmers or farm staff who knew them and trusted them to make their payments. Conflict and dissatisfaction arose in a few instances when participants disagreed with farmers or farm staff regarding payments.

\section{Logistical interactions}

Several participants described their farmers as 'accommodating' and believed that their relationship with the farmer was a significant aspect of their CSA experience. Participants found newsletters and emails regarding upcoming produce and flexibility regarding pick-up timing to be useful. Some participants described close relationships engendered by interactions during weekly pick-ups as farmers got to know their personal lives, dropped off produce at their homes and occasionally provided free produce in addition to the CSA share.

\section{Availability: variety and quantity of community- supported agriculture produce}

Many farms offered different share sizes and participants could choose the one that best fit their families. Across all focus groups, participants thought that their CSA size was adequate or more than adequate, and no one stated that they desired to increase their share size. During the season, several participants elected to decrease their share size due to the abundant quantity of vegetables:

'I got two. I didn't know how much stuff is actually in a share. You know, it said so many units, but here I'm thinking okay we're going to get maybe three apples. [...] I didn't think those boxes were going to be packed to the max.' (NY, Farm 1)

As indicated in the above quote, some participants were unable to accurately envision and plan for the volume and variety of products prior to the start of the season. Some participants expressed frustration that their shares had 'a lot of one thing and a little bit of something else'. Although some farms sent out emails or letters announcing weekly share items, the quantity of each type of produce was still unexpected, requiring additional meal planning and shopping to use share contents before they spoiled. Participants sometimes compared the contents of their share with that of others during pick-up, noticing that shares were not all always the same.

Participants had distinct experiences based on whether their CSA farm utilized pre-packed shares or if members chose their own produce from a weekly selection:

'I mean to a certain extent it was fun to have like new things, but [...] everybody agrees, there should be some sort of option like if there's something you're definitely not going to eat [...] because growing the things that we're not going to touch is kind of wasteful.' (NC, Farm 1)

In contrast to participants with preselected shares, participants who joined farms with a self-select option did not express a sense of being overwhelmed with a particular type of produce. However, some did express frustration about the lack of variety for those who came later during the pick-up time once supplies had been depleted.

\section{Discussion}

The current paper assessed the effects of a CO-CSA intervention trial on perceived food access among low-income families using five dimensions of access: availability, accessibility, affordability, acceptability and accommodation. This framework revealed several key factors, which illustrate the potential of CSA participation to facilitate better fruit and vegetable access for low-income families. The present study is the one of the first to explore the experiences of lowincome families with children taking part in a CO-CSA programme and provides useful information on the unique barriers faced by this population. While some of these findings are similar to those of previous studies, we highlight several specific findings that are significant contributions to the literature.

We note that weekly or biweekly payments may not fully accommodate the needs of low-income participants with children. Because the traditional lump sum payment structure of CSA can be a deterrent for low-income families ${ }^{(20)}$, F3HK used a weekly or biweekly payment structure. This may make payments more difficult at the end of the month when SNAP (Supplemental Nutrition Assistance Program) benefits are exhausted. The cyclic effect of monthly SNAP disbursement on food purchasing has been previously described ${ }^{(29,30)}$; however, we are the first to note it within the context of a subsidized CSA. While weekly or biweekly payments may render subsidized CSA more accessible to low-income individuals, further accommodation such as the option for a monthly payment may be necessary to further facilitate CSA membership in this population.

Another significant finding is that low-income participants in the present study appeared to be more satisfied with their CSA experience when they were able to choose their own produce. Unlike a traditional CSA, in which the 
farmer usually selects the produce, some F3HK farms offered a market-style share in which participants selfselect produce items. Participants in our study who had this option appreciated being able to self-select items, consistent with prior studies ${ }^{(17,24,31)}$. In contrast, those with farmer-selected produce articulated frustrations with unpredictable types and quantities of vegetables and fruits, stating a desire for greater choice.

F3HK focus group participants also mentioned transportation challenges to share pick-up and poor organization at the pick-up site as barriers to access. These barriers have been described in other studies of subsidized CSA for low-income participants ${ }^{(17,24)}$. However, these are factors that also deter higher-income consumers from purchasing or renewing CSA membership. It has been shown previously that CSA members typically join because they value its benefits to local farms, the environment and rural economies ${ }^{(32,33)}$. They are generally less concerned with cost and may be more willing to tolerate the inconveniences of shopping at direct-to-consumer venues ${ }^{(32)}$. In contrast, participants in subsidized CSA studies, including F3HK, are more likely to say they enrolled due to lower produce prices and may expect the CSA to be as convenient as conventional markets in terms of distance to travel, hours of operation, ability to self-select and yearround availability of a wide variety of items ${ }^{(34)}$. Like families with higher incomes, some low-income families might not choose a CSA even if most access barriers were diminished.

It is important to note that CSA were historically set up to limit the risks local farmers faced by providing a consistent revenue stream, allowing flexibility in the provision of produce depending on growing conditions and providing an alternative to the resources required to staff a farmers' market or deliver produce ${ }^{(35)}$. For the CO-CSA model to work for both low-income consumers and producers, it must meet needs for accessibility, affordability, acceptability, accommodation and availability, while still providing farms some advantages of the original CSA model. These dual aims were implemented as part of the F3HK intervention trial, which paid the farm $50 \%$ of share cost at the beginning of the growing season and allowed participants to pay the balance in instalments. As part of the F3HK trial, we are assessing farmer perspectives on intervention participants as customers, the economic returns to CO-CSA partner farms and the potential economic impact of CO-CSA on communities under various policy scenarios.

As direct-to-consumer marketing and sales have increased there is greater local, state and federal support of these programmes ${ }^{(36)}$. Our work suggests that CSA subsidies lower some, but not all, access barriers for lowincome families. Some of the barriers we identified could potentially be addressed through multisector collaborations, such as partnerships with local schools or WIC (Special Supplemental Nutrition Program for Women,
Infants, and Children) offices to permit produce pick-up at more convenient locations ${ }^{(34)}$. Further, our findings suggest that small modifications to existing SNAP rules may support CSA participation by low-income families. Beginning in 2013, SNAP could be used to pay for produce purchased through CSA, but SNAP rules prohibit CSA from accepting payment more than $14 \mathrm{~d}$ before pick-up ${ }^{(37)}$. Extending this payment window by $14 \mathrm{~d}$ would allow farms to accept monthly CSA payments, thereby easing logistical burdens of payment plans for farms while still offering flexibility for low-income families with limited resources.

Key strengths of the present study are the multisite design utilizing local farms and the diversity of participants. Another strength is our rigorous and consistent approach to data collection and analysis. All facilitators participated in a focused training to help standardize facilitation across states. This training included discussion of how to establish a welcoming atmosphere, remain neutral, ask effective probes and manage group dynamics. In addition, peer debriefing and the collaboration of multiple co-authors on codebook development and coding made possible the inclusion of multiple perspectives ${ }^{(33)}$. Study limitations include the potential for social desirability bias and the possibility that participants who participated in the focus groups may not have been fully representative of all intervention participants or lowincome populations.

\section{Conclusion}

CO-CSA has the potential to address socio-economic disparities in food access by improving the affordability and availability of produce for low-income families. However, access barriers remain as families attempt to incorporate CSA share pick-up into regular travel patterns and include unfamiliar produce into meal planning on a limited budget. Additional accommodations such as more flexible payment structures and self-selection of produce may further improve access; however, addressing these concerns must be balanced by limiting the financial risk to farms. As support grows for CSA at the state and local level, it is important to emphasize the importance of developing and evaluating CSA models which simultaneously address the access barriers of low-income families as well as the economic needs of local farms.

\section{Acknowledgements}

Acknowledgements: The authors thanks Leah Connor, Salem Carriker, Judy Ward and Jennifer Garner, of Cornell University, for their assistance. Financial support: This work was supported by the National Institutes of Health National Research Service Award (M.J.W., grant number 
T32-HP14001) and the National Institute of Food and Agriculture, US Department of Agriculture (grant number 2015-68001-23230). The funders had no role in study design, collection, analysis and interpretation, the writing of the report and the decision to submit for publication. Conflict of interest: The authors have no conflicts of interest to disclose. Authorship: M.J.W., S.B.J.P., K.L.H., J.K., M.S., A.S.A., J.T.M. and R.A.S. conceived of the study; R.A.S., J.K., J.T.M., E.H.M., M.S. and W.W. participated in data collection; M.J.W., S.B.J.P. and J.T.M. developed the coding approach; M.J.W. and S.B.J.P. performed all data analysis; all authors provided critical feedback on data analysis and interpretation and manuscript preparation, and approved the final manuscript as written. Ethics of buman subject participation: This study was conducted according to the guidelines laid down in the Declaration of Helsinki and all procedures involving human subjects were approved by the institutional review boards at the University of Vermont (CHRBS 16-393) and Cornell University (protocol ID \#1501005266). Written informed consent was obtained from all subjects.

\section{References}

1. Ledoux TA, Hingle MD \& Baranowski T (2011) Relationship of fruit and vegetable intake with adiposity: a systematic review. Obes Rev 12, e143-e150.

2. Aune D, Giovannucci E, Boffetta P et al. (2017) Fruit and vegetable intake and the risk of cardiovascular disease, total cancer and all-cause mortality - a systematic review and dose-response meta-analysis of prospective studies. Int $J$ Epidemiol 46, 1029-1056.

3. James WP, Nelson M, Ralph A et al. (1997) Socioeconomic determinants of health. The contribution of nutrition to inequalities in health. BMJ 314, 1545-1549.

4. Giskes K, Avendano M, Brug J et al. (2010) A systematic review of studies on socioeconomic inequalities in dietary intakes associated with weight gain and overweight/obesity conducted among European adults. Obes Rev 11, 413-429.

5. Dubowitz T, Heron M, Bird CE et al. (2008) Neighborhood socioeconomic status and fruit and vegetable intake among whites, blacks, and Mexican Americans in the United States. Am J Clin Nutr 87, 1883-1891.

6. Walker RE, Keane CR \& Burke JG (2010) Disparities and access to healthy food in the United States: a review of food deserts literature. Health Place 16, 876-884.

7. Pomerleau J, Lock K, Knai C et al. (2005) Interventions designed to increase adult fruit and vegetable intake can be effective: a systematic review of the literature. J Nutr $\mathbf{1 3 5}$, 2486-2495.

8. Hodder RK, O'Brien KM, Stacey FG et al. (2017) Interventions for increasing fruit and vegetable consumption in children aged five years and under. Cochrane Database Syst Rev 9, CD008552.

9. Penchansky R \& Thomas JW (1981) The concept of access: definition and relationship to consumer satisfaction. Med Care 19, 127-140.

10. Caspi CE, Sorensen G, Subramanian SV et al. (2012) The local food environment and diet: a systematic review. Health Place 18, 1172-1187.

11. Allen P (2004) Together at the Table: Sustainability and Sustenance in the American Agrifood System. University Park, PA: Pennsylvania State University Press.
12. Alkon AH \& Agyeman J (2011) Cultivating Food Justice: Race, Class, and Sustainability. Cambridge, MA: MIT Press.

13. Ruelas V, Iverson E, Kiekel $\mathrm{P}$ et al. (2012) The role of farmers' markets in two low income, urban communities. J Community Health 37, 554-562.

14. Wilkins JL, Farrell TJ \& Rangarajan A (2015) Linking vegetable preferences, health and local food systems through community-supported agriculture. Public Health Nutr 18, 2392-2401.

15. Jilcott Pitts SB, Wu Q, McGuirt JT et al. (2013) Associations between access to farmers' markets and supermarkets, shopping patterns, fruit and vegetable consumption and health indicators among women of reproductive age in eastern North Carolina, USA. Public Health Nutr 16, 1944-1952.

16. Vasquez A, Sherwood NE, Larson N et al. (2017) Community-supported agriculture as a dietary and health improvement strategy: a narrative review. J Acad Nutr Diet 117, 83-94.

17. Galt RE, Bradley K, Christensen L et al. (2017) What difference does income make for community supported agriculture (CSA) members in California? Comparing lowerincome and higher-income households. Agric Hum Values 34, 435-452.

18. Perez J, Allen P \& Brown M (2003) Community Supported Agriculture on the Central Coast: The CSA Member Experience. Research Brief\#1, Winter 2003. Santa Cruz, CA: Center for Agroecology \& Sustainable Food Systems, University of California-Santa Cruz.

19. Constance DH \& Jordan JL (2008) Motivations for participating in community supported agriculture and their relationship with community attachment and social capital. South Rural Sociol 23, 94-115.

20. Freedman DA, Vaudrin N, Schneider C et al. (2016) Systematic review of factors influencing farmers' market use overall and among low-income populations. J Acad Nutr Diet 116, 1136-1155.

21. Olsho LE, Payne GH, Walker DK et al. (2015) Impacts of a farmers' market incentive programme on fruit and vegetable access, purchase and consumption. Public Health Nutr 18, 2712-2721.

22. Young CR, Aquilante JL, Solomon S et al. (2013) Improving fruit and vegetable consumption among low-income customers at farmers markets: Philly Food Bucks, Philadelphia, Pennsylvania, 2011. Prev Chronic Dis 10, E166.

23. Lang KB (2010) The changing face of community-supported agriculture. Cult Agric 32, 17-26.

24. Quandt SA, Dupuis J, Fish C et al. (2013) Feasibility of using a community-supported agriculture program to improve fruit and vegetable inventories and consumption in an underresourced urban community. Prev Chronic Dis 10, E136.

25. Andreatta S, Rhyne M \& Dery N (2008) Lessions learned from advocating CSAs for low-income and food insecure households. South Rural Sociol 23, 116-148.

26. Wang W \& Kolodinsky JSR (2016) Identifying reasons for attrition from subsidized community supported agriculture membership among limited resource populations. Lecture presented at Scarborough Fare: Global Foodways and Local Foods in a Transnational City, University of Toronto Scarborough, Scarborough, Ontario, Canada, 22-25 June 2016.

27. Seguin RA, Morgan EH, Hanson KL et al. (2017) Farm Fresh Foods for Healthy Kids (F3HK): an innovative community supported agriculture intervention to prevent childhood obesity in low-income families and strengthen local agricultural economies. BMC Public Health 17, 306.

28. Creswell JW \& Miller DL (2000) Determining validity in qualitative inquiry. Theory Pract 39, 124-130. 
29. Hastings J \& Washington E (2010) The first of the month effect: consumer behavior and store responses. Am Econ J Econ Policy 2, 142-162.

30. Wilde P \& Ranney C (2000) The monthly food stamp cycle: shopping frequency and food intake decisions in an endogenous switching regression framework. Am J Agric Econ 82, 200-213.

31. Cotter EW, Teixeira C, Bontrager A et al. (2017) Low-income adults' perceptions of farmers' markets and communitysupported agriculture programmes. Public Health Nutr 20, $1452-1460$

32. Galt R \& Galt RE (2015) Counting and mapping community supported agriculture (CSA) in the United States and California: contributions from critical cartography/GIS. ACME: Int J Crit Geogr 10, 131-162.

33. Pole A \& Kumar A (2015) Segmenting CSA members by motivation: anything but two peas in a pod. BrFood J117, 1488-1505.
34. Hoffman JA, Agrawal T, Wirth C et al. (2012) Farm to family: increasing access to affordable fruits and vegetables among urban Head Start families. J Hunger Environ Nutr 7, 165-177.

35. Guthman J, Morris AW \& Allen P (2006) Squaring farm security and food security in two types of alternative food institutions. Rural Sociol 71, 662-684.

36. Martinez S, Hand M, Da Pra M et al. (2010) Local Food Systems: Concepts, Impacts, and Issues. Economic Research Report no. ERR-97. Washington, DC: US Department of Agriculture, Economic Research Service.

37. US Department of Agriculture, Food and Nutrition Service (2018) Supplemental Nutrition Assistance Program (SNAP): Agricultural Act of 2014 Nondiscretionary Provisions. Final Rule. September 3, 2015. https://www.federalregister.gov/ documents/2015/09/03/2015-21906/supplemental-nutri tion-assistance-program-snap-agricultural-act-of-2014-non discretionary-provisions (accessed June 2018). 